\title{
ANALISIS KUALITAS PELAYANAN PUSKESMAS BERDASARKAN INDEKS KEPUASAN MASYARAKAT DAN IMPORTANCE PERFORMANCE MATRIX (Studi Kasus: Puskesmas 24 Jam Tingkat Kecamatan di Jakarta)
}

\author{
Lithrone Laricha ${ }^{1)}$, Andres ${ }^{1)}$ dan Hilda Setia Dharma ${ }^{2)}$ \\ ${ }^{1)}$ Program Studi Teknik Industri Universitas Tarumanagara, Jakarta \\ ${ }^{2)}$ Alumni Program Studi Teknik Industri Universitas Tarumanagara, Jakarta \\ e-mail: laricha_salomon@yahoo.com
}

\begin{abstract}
ABSTRAK
Kesehatan adalah kebutuhan dasar setiap orang. Salah satu jenis pelayanan kesehatan dalam lingkup terkecil adalah Puskesmas. Pelayanan di Puskesmas terus ditingkatkan terutama dalam segi fasilitas sarana dan prasarana, tetapi beberapa masyarakat masih menganggap puskesmas kurang kompeten. Berdasarkan hal tersebut, penelitian dilakukan untuk mengetahui Indeks Kepuasan Masyarakat (IKM) terhadap pelayanan di Puskesmas 24 jam tingkat kecamatan di Jakarta dari sisi lain selain fasilitas sarana dan prasarana dan juga untuk menentukan strategi pengembangan untuk meningkatkan kualitas pelayanan Puskesmas. Dari hasil kuesioner yang disebar kepada 384 responden di 42 Puskesmas tingkat kecamatan di Jakarta didapatkan nilai IKM sebesar 81,15 dan termasuk golongan Baik. Setelah didapatkan nilai IKM, maka selanjutnya data diolah dengan menggunakan Importance Performance Analysis sehingga didapatkan Importance Performance Matrix. Berdasarkan hasil Importance Performance Matrix, didapatkan unsur A1, A6, A10, dan A11 menjadi unsur yang harus lebih diperhatikan karena dianggap penting tetapi pelaksanaannya masih belum sesuai dengan harapan masyarakat. Strategi pengembangan akan dilakukan dengan menggunakan metode Hoshin Kanri.
\end{abstract}

Kata kunci: Puskesmas, IKM, IPA, Hoshin Kanri.

\begin{abstract}
Health is a basic need of every person. One type of health care in the smallest scope is health center. Services at the Puskesmas (health center) is continously improved, especially in terms of facilities and infrastructures, but some people still think that health center is less competent. Based on that problem, research conducted to examined the Community Satisfaction Index (CSI) at 24 hours health center services at district level in Jakarta on the other side besides infrastructure facilities and also to determine the development strategy to improve the quality of health center services. CSI value obtained from the questionnaire distributed to 384 respondents in 42 health centers in Jakarta district level and including in good category with the value obtained IKM of 81.15. After the CSI value is obtained, then the data will be processed using by Importance Performance Analysis to obtain Importance Performance Matrix. Based on Importance Performance Matrix result, A1, A6, A10, and A11 become elements that should be considered because it is important, but its implementation still not in accordance with the expectations of society. The development strategy will be carried out by using Hoshin Kanri.
\end{abstract}

Keywords: Puskesmas, CSI, IPA, Hoshin Kanri

\section{PENDAHULUAN}

Pelayanan kesehatan yang bermutu adalah kebutuhan dasar setiap orang. Salah satu jenis pelayanan kesehatan yang diolah oleh pemerintah adalah Puskesmas (Pusat Kesehatan Masyarakat). Puskesmas adalah pelayanan kesehatan dalam lingkup kelurahan atau kecamatan sehingga menjadi tingkatan pertama dalam pelayanan kesehatan kepada masyarakat di wilayah tersebut, maka Puskesmas juga berperan sebagai garda pertama untuk mengurangi beban rumah sakit. Tetapi beberapa masyarakat masih meremehkan peranan puskesmas. Hal ini dikatakan Dokter Poli Rujukan Puskesmas Tebet, Sri Sudewi bahwa beberapa pasien yang datang kadang memilih ingin langsung dirujuk ke rumah sakit begitu diagnosa selesai, padahal masih dapat ditangani di Puskesmas. Peranan penting Puskesmas sebagai garda pertama pelayanan kesehatan masyarakat telah didukung dengan fasilitas yang lengkap dan bagus, terutama pada Puskesmas tingkat kecamatan yang melakukan pelayanan 24 jam. Tetapi tingkat kepuasan masyarakat pengguna layanan kesehatan di Puskesmas dari sisi mutu pelayanan, seperti 
keramahan, kesopanan, kecepatan pelayanan, prosedur pelayanan, dan lainnya belum diketahui. Berdasarkan latar belakang diatas dilakukan penelitian untuk mengetahui tingkat kepuasan masyarakat pengguna layanan kesehatan terhadap mutu pelayanan di Puskesmas 24 jam tingkat kecamatan yang ada di Jakarta dengan di uji menggunakan Pedoman Umum Penyusunan Indeks Kepuasan Masyarakat Unit Pelayanan Instansi Pemerintah sesuai dengan Keputusan Menteri Pendayagunaan Aparatur Negara No. 25 Tahun 2004. Penelitian ini bertujuan untuk mengetahui tingkat kesesuaian antara kinerja dan harapan dari masyarakat pengguna jasa layanan Puskesmas 24 jam tingkat kecamatan di Jakarta, untuk mengetahui nilai indeks kepuasan masyarakat, dan menentukan strategi pengembangan untuk meningkatkan kualitas pelayanan Puskesmas.

\section{TINJAUAN PUSTAKA}

\section{Puskesmas}

Puskesmas juga dapat didefinisikan sebagai fasilitas pelayanan kesehatan yang menyelenggarakan upaya kesehatan masyarakat dan upaya kesehatan perseorangan tingkat pertama, dengan lebih mengutamakan upaya promotif dan preventif, untuk mencapai derajat kesehatan yang setinggi-tingginya di wilayah kerjanya [1].

\section{Kepuasan Pasien}

Kepuasan pasien adalah keluaran dari layanan kesehatan dan suatu perubahan dari sistem layanan kesehatan yang ingin dilakukan tidak mungkin tepat sasaran dan berhasil tanpa melakukan pengukuran kepuasan pasien [2]. Kepuasan pasien dapat diukur dengan indikator berikut:

a. Kepuasan terhadap akses layanan kesehatan

b. Kepuasan terhadap mutu layanan kesehatan

c. Kepuasan terhadap proses layanan kesehatan, termasuk hubungan antarmanusia

d. Kepuasan terhadap sistem layanan kesehatan

Konsep multidimensi kepuasan pasien menurut Imbalo S. Pohan [2] dapat dilihat pada Gambar 1.

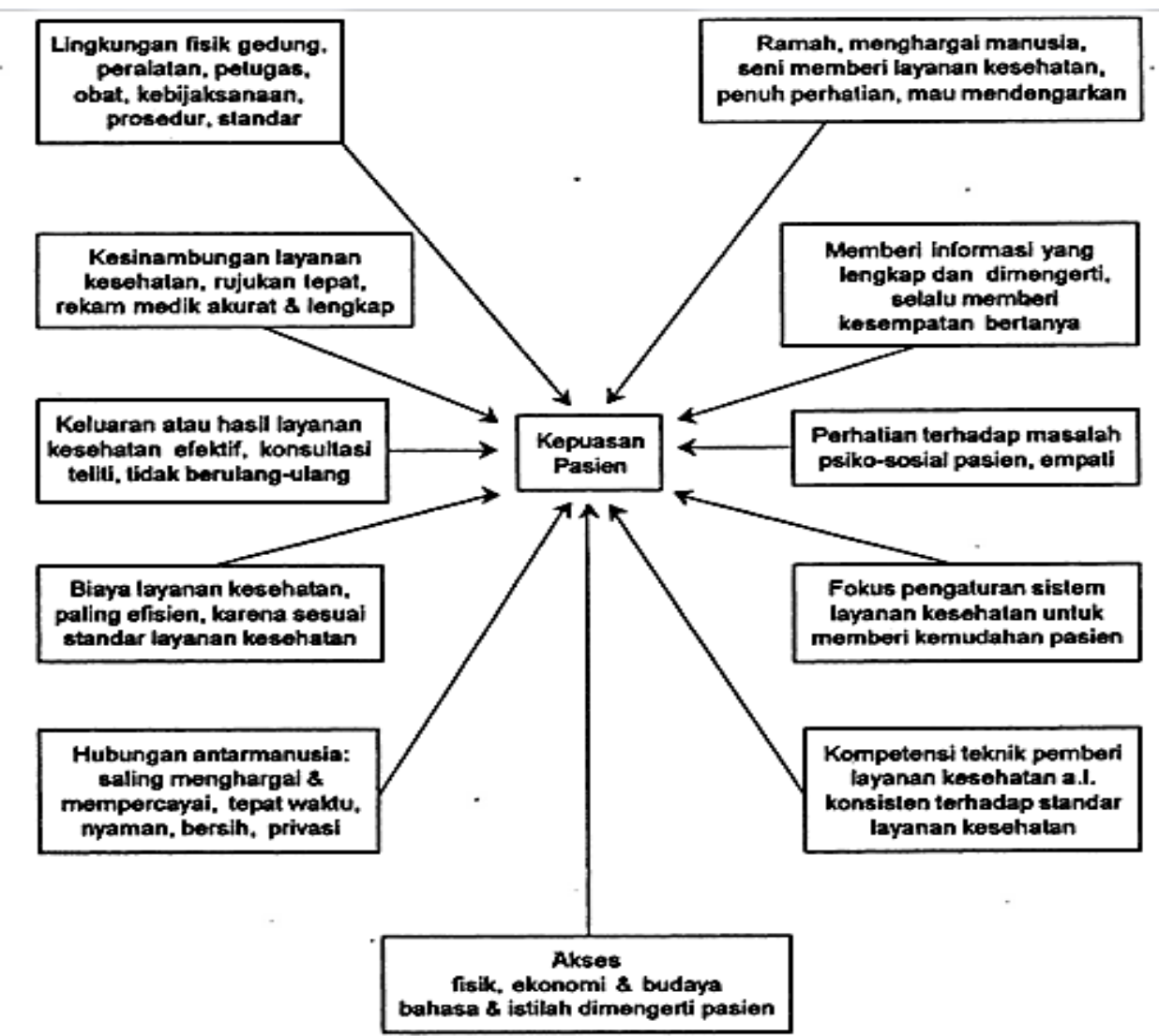

Gambar 1. Konsep Multidimensi Kepuasan Pasien 


\section{Validitas dan Reliabilitas}

Validitas atau kesahihan adalah menunjukkan sejauh mana suatu alat ukur mampu mengukur apa yang ingin diukur [3]. Data dianggap valid jika koefisien korelasi produk moment $(r$ hitung) $>r$ tabel.

Reliabilitas adalah untuk mengetahui sejauh mana hasil pengukuran tetap konsisten, apabila dilakkukan pengukuran dua kali atau lebih terhadap gejala yang sama dengan menggunakan alat pengukuran yang sama pula. Dengan menggnakan teknik alpha cronbach, kriteria suatu instrumen penelitian dikatakan reliable bila koefisien reliabilitas $>0,6$ [4].

\section{Indeks Kepuasan Masyarakat}

Berdasarkan Keputusan Menteri Pendayagunaan Aparatur Negara Republik Indonesia No. KEP/25/M.PAN/2/2004 tentang "Pedoman Umum Penyusunan Indeks Kepuasan Masyarakat Unit Pelayanan Instalasi Pemerintah” yang dimaksud Indeks Kepuasan Masyarakat (IKM) adalah data dan informasi tentang tingkat kepuasan masyarakat yang diperoleh dari hasil pengukuran secara kuantitatif dan kualitatif atas pendapat masyarakat dalam memperoleh pelayanan dari aparatur penyelenggara pelayanan publik dengan membandingkan antara harapan dan kebutuhannya [5].

Nilai IKM dihitung dengan menggunakan "nilai rata-rata tertimbang" masing-masing unsur pelayanan. Dalam penghitungan indeks kepuasan masyarakat terhadap 14 unsur pelayanan yang dikaji, setiap unsur pelayanan memiliki penimbang yang sama dengan rumus sebagai berikut:

Bobot Nilai Rata - Rata Tertimbang $=\frac{\text { Jumlah Bobot }}{\text { Jumlah Unsur }}$

Untuk memperoleh nilai IKM unit pelayanan digunakan pendekatan nilai rata-rata tertimbang dengan rumus sebagai berikut:

$\mathrm{IKM}=\frac{\text { Total dari Nilai Persepsi Per Unsur }}{\text { Total Unsur yang Terisi }} \times$ Nilai Penimbang

Untuk memudahkan interpretasi terhadap penilaian IKM antara 25-100 maka hasil penilaian tersebut diatas dikonversikan dengan nilai dasar 25, dengan rumus sebagai berikut:

\section{IKM Konversi = IKM Unit Pelayanan x 25}

Mengingat unit pelayanan mempunyai karakteristik yang berbeda-beda, maka setiap unit pelayanan dimungkinkan untuk :

a. Menambah unsur yang dianggap relevan

b. Memberikan bobot yang berbeda terhadap 14 (empat belas) unsur yang dominan dalam unit pelayanan, dengan cacatan jumlah bobot seluruh unsur tetap 1 .

Nilai persepsi, nilai interval IKM, nilai interval konversi IKM, hingga kinerja unit pelayanan dapat dilihat pada Tabel 1 .

\section{Importance Performance Analysis (IPA)}

Menurut Philip Kotler analisis arti penting-kinerja (importance-performance analysis) dapat digunakan untuk merangking berbagai elemen dari kumpulan jasa dan mengidentifikasi tindakan yang diperlukan. Pada analisis Importance-Performance Analysis, dilakukan pemetaan menjadi 4 kuadran untuk seluruh variabel yang mempengaruhi kualitas pelayanan [6]. Pembagian kuadran dalam ImportancePerformance Analysis dapat dilihat pada Gambar 2.

Tabel 1. Nilai Persepsi, Interval IKM, Interval Konversi IKM, Mutu Pelayanan dan Kinerja Unit Pelayanan

\begin{tabular}{ccccc}
\hline $\begin{array}{c}\text { Nilai } \\
\text { Persepsi }\end{array}$ & $\begin{array}{c}\text { Nilai Interval } \\
\text { IKM }\end{array}$ & $\begin{array}{c}\text { Nilai Interval } \\
\text { Konversi IKM }\end{array}$ & $\begin{array}{c}\text { Mutu } \\
\text { Pelayanan }\end{array}$ & $\begin{array}{c}\text { Kinerja Unit } \\
\text { Pelayanan }\end{array}$ \\
\hline 1 & $1,00-1,75$ & $25,00-43,75$ & $\mathrm{D}$ & Tidak Baik \\
2 & $1,76-2,50$ & $43,76-62,50$ & $\mathrm{C}$ & Kurang Baik \\
3 & $2,51-3,25$ & $62,51-81,25$ & $\mathrm{~B}$ & Baik \\
4 & $3,26-4,00$ & $81,26-100,00$ & $\mathrm{~A}$ & Sangat Baik \\
\hline
\end{tabular}




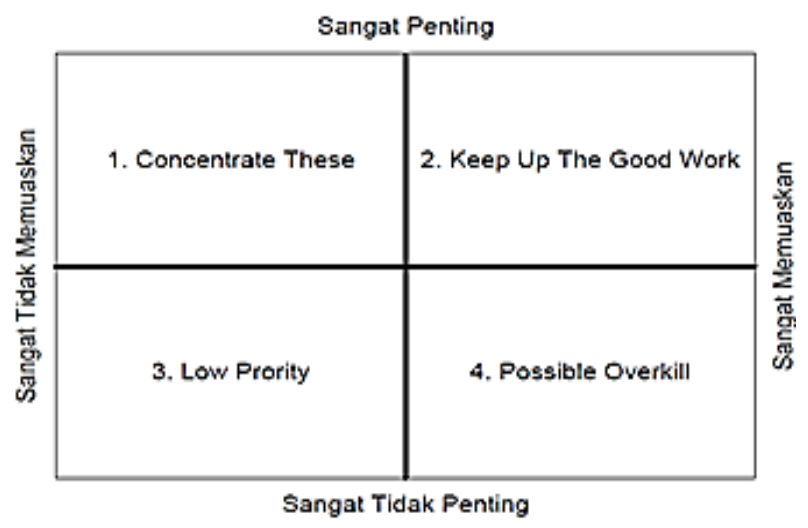

Gambar 2. Importance-Performance Matrix

Keterangan:

a. Kuadran 1 (Concentrate These)

Memuat faktor-faktor yang dianggap penting oleh pelanggan, tetapi pada kenyataannya faktor-faktor ini belum sesuai dengan harapan pelanggan. Variabelvariabel yang masuk dalam kuadran ini harus ditingkatkan.

b. Kuadran 2 (Keep Up The Good Work) Memuat faktor-faktor yang dianggap penting oleh pelanggan, dan faktor-faktor yang dianggap pelanggan sudah sesuai dengan yang dirasakannya sehingga tingkat kepuasannya relatif lebih tinggi.

c. Kuadran 3 (Low Priority)

Memuat faktor-faktor yang dianggap kurang penting oleh pelanggan, dan pada kenyatannya kinerjanya tidak terlalu istimewa. Peningkatan variabel-variabel yang termasuk dalam kuadran ini dapat dipertimbangkan kembali karena pengaruhnya terhadap manfaat yang dirasakan oleh pelanggan sangat kecil.

d. Kuadran 4 (Possible Overkill)

Memuat faktror-faktor yang dianggap kurang penting oleh pelanggan, dan dirasakan terlalu berlebihan. Variabelvariabel yang termasuk dalam kuadran ini dapat dikurangi agar perusahaan dapat menghemat biaya.

\section{Hoshin Kanri}

Metode hoshin kanri ditemukan oleh Ishikawa yang berpendapat bahwa setiap orang dalam organisasi adalah ahli dalam pekerjaannya sehingga kekuatan bersama yang dimiliki oleh seluruh organisasi akan membantu tercapainya sasaran perusahaan. dimulai dari sasaran global perusahaan (site wide) yang kemudian diturunkan ke sasaran per individual departement[7]. Penurunan ini memastikan bahwa apa yang dicapai oleh departemen harus sejalan dengan sasaran perusahaan, dan jika semua key performance indicator di tingkat departemen ini tercapai, maka sasaran global juga akan tercapai. Berikut ini merupakan $X$ Matrix yang digunakan dalam hoshin kanri dalam pengambilan keputusan yang lebih baik dapat dilihat pada Gambar 3.

\section{METODE PENELITIAN}

Penelitian ini dilakukan di 42 Puskesmas 24 jam tingkat kecamatan di DKI Jakarta. Proses pengumpulan data dilakukan dengan menggunakan instrumen berupa kuesioner yang disebar kepada 384 responden baik pasien maupun pendamping pasien yang menggunakan jasa Puskesmas 24 jam tingkat kecamatan di Jakarta. Data yang diperoleh dari hasil penyebaran kuesioner yaitu berupa tingkat kepentingan dan tingkat kepuasan pengguna layanan jasa Puskesmas 24 jam tingkat kecamatan di Jakarta. Data yang telah terkumpul itu lalu diolah untuk memastikan bahwa data tersebut valid, reliable, dan berdistribusi normal, setelah itu dilakukan uji hipotesis untuk mengetahui apakah unsur-unsur indeks kepuasan masyarakat berpengaruh secara signifikan terhadap kepuasan masyarakat. Selanjutnya, dilakukan proses perhitungan sehingga didapatkan nilai Indeks Kepuasan Masyarakat (IKM), kemudian digunakan metode Importance Performance Analysis (IPA) untuk mengetahui tingkat kesesuaian antara tingkat kepentingan dan tingkat kepuasan dari masyarakat pengguna layanan Puskesmas 24 jam tingkat kecamatan di Jakarta. Setelah diketahui faktor-faktor mana yang harus dilakukan peningkatan, maka dilakukan strategi pengembangan dengan metode Hoshin Kanri. Flowchart untuk metode penelitian dapat dilihat pada Gambar 4. 
Analisis Kualitas Pelayanan Puskesmas Berdasarkan Indeks Kepuasan Masyarakat dan Importance Performance Matrix (Studi Kasus: Puskesmas 24 Jam Tingkat Kecamatan di Jakarta)

Lithrone Laricha, Andres dan Hilda Setia Dharma
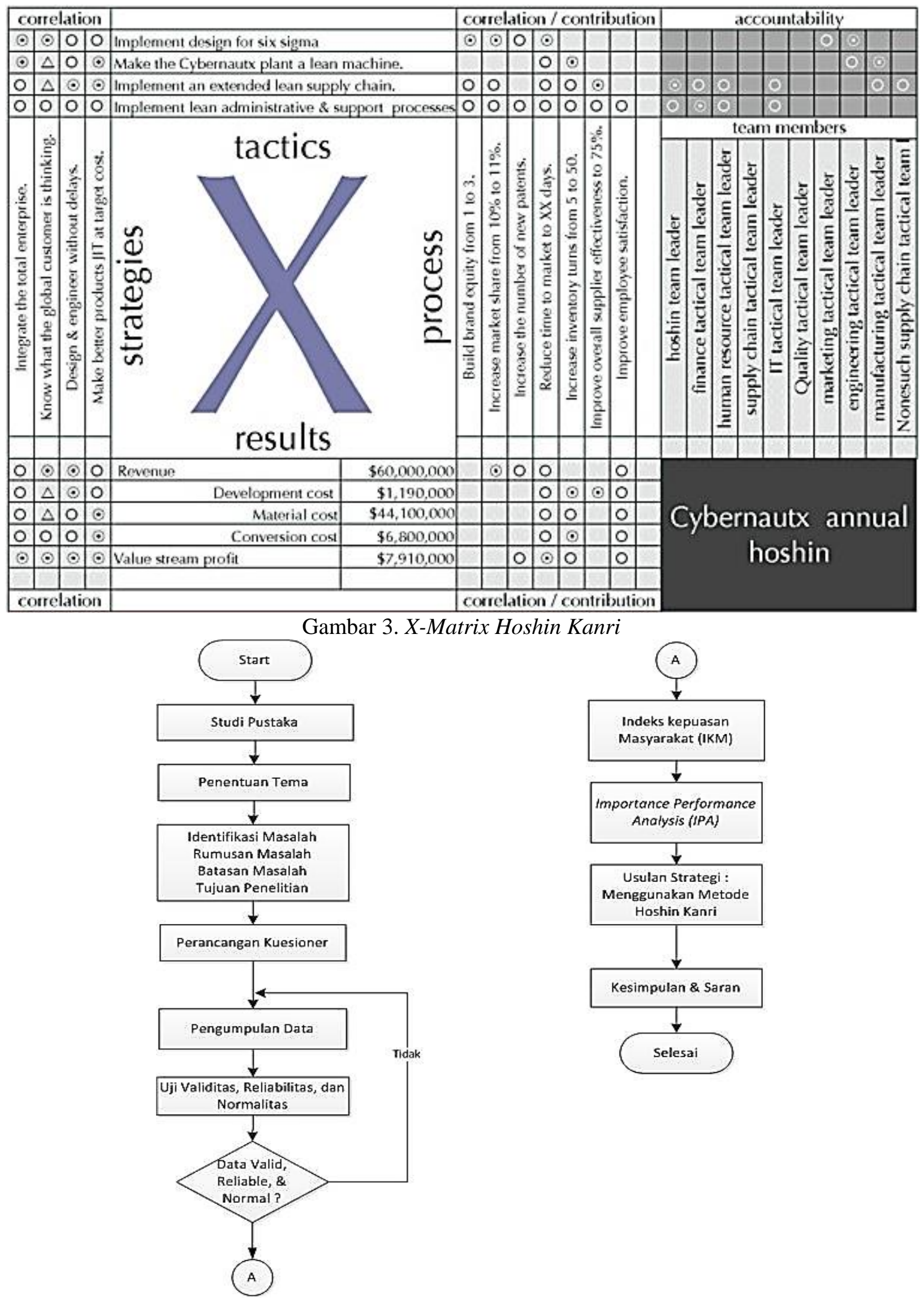

Gambar 4. Flowchart Metode Penelitian 


\section{HASIL DAN PEMBAHASAN Uji Validitas dan Reliabilitas}

Dari data hasil penyebaran kuesioner, didapatkan 384 responden, selanjutnya dilakukan uji validitas untuk mengetahui apakah ada atribut yang harus dibuang atau diganti karena dianggap tidak relevan. Atribut tersebut dinyatakan valid apabila $r$ hitung $>r$ tabel. Hasil uji validitas kuesioner didapatkan bahwa nilai $r$ hitung dari seluruh atribut lebih besar dari nilai $r$ tabel $(0,100)$ sehingga seluruh atribut dinyatakan valid.

Selanjutnya dilakukan uji reliabilitas untuk mengetahui apakah instrumen memiliki keandalan sebagai alat ukur. Instrumen dianggap reable apabila nilai koefisien reliabilitas $r>0,6$. Hasil uji reliabilitas data kuesioner didapatkan nilai cronbach's alpha untuk koefisien reliabilitas kepentingan sebesar 0,878 dan cronbach's alpha untuk koefisien reliabilitas kepuasan sebesar 0,723. Nilai cronbach's alpha untuk koefisien reliabilitas kepentingan dan koefisien reliabilitas kepuasan lebih besar dari 0,6 sehingga data dinyatakan reable.

\section{Uji Normalitas}

Dalam melakukan pengukuran Indeks Kepuasan Masyarakat (IKM) sesuai dengan Keputusan Menteri PAN Nomor: 63/KEP/M.PAN/7/2003, terdapat 14 unsur indeks kepuasan masyarakat, tetapi dalam penelitian ini hanya diteliti 12 unsur saja karena ingin diketahui indeks kepuasan masyarakat dari sisi lain selain fasilitas yang disediakan di Puskesmas. Unsur-unsur indeks kepuasan masyarakat yang diteliti adalah prosedur pelayanan, persyaratan pelayanan, kejelasan petugas pelayanan, kedisiplinan petugas pelayanan, kedisiplinan petugas pelayanan, tanggung jawab petugas pelayanan, kemampuan petugas pelayanan, kecepatan pelayanan, keadilan mendapatkan pelayanan, kesopanan dan keramahan petugas, kewajaran biaya pelayanan, kepastian biaya pelayanan, dan kepastian jadwal pelayanan.

Uji normalitas dilakukan untuk mengetahui apakah data sampel yang digunakan mengikuti atau mendekati distribusi normal. Data berdistribusi normal adalah salah satu syarat data parametrik sehingga data memiliki karakteristik empirik yang mewakili populasi [8]. Untuk uji normalitas digunakan hipotesis awal sebagai berikut:

$\mathrm{H}_{0}=$ populasi berdistribusi normal

$\mathrm{H}_{1}=$ populasi tidak berdistribusi normal

Dengan menggunakan $\alpha=5 \% \mathrm{H}_{0}$ akan diterima jika nilai hasil uji normalitas lebih besar dari nilai alpha 0,05 [9].

Hasil uji Kolmogorov-Smirnov terhadap variabel kepuasan masyarakat sebesar 0,104, sedangkan hasil uji Kolmogorof-Smirnov terhadap masing-masing unsur indeks kepuasan masyarakat adalah 0,$303 ; 0,440 ; 0,328 ; 0,445$; 0,383; 0,423; 0,220; 0,337; 0,356; 0,313; 0,366; 0,487 artinya $(\mathrm{p}>0,05)$, maka terima $\mathrm{H}_{0}$ atau populasi dinyatakan berdistribusi normal.

\section{Indeks Kepuasan Masyarakat}

Nilai Indeks Kepuasan Masyarakat (IKM) dihitung dengan menggunakan "nilai rata-rata tertimbang” masing-masing atribut.

Dalam penelitian ini, nilai rata-rata tertimbang $=\frac{1}{14}=0,071$

Berikut adalah nilai rata-rata kepuasan masyarakat per atribut dapat dilihat pada Tabel 2.

Tabel 2. Nilai Rata-Rata Kepuasan Masyarakat

\begin{tabular}{ccc}
\hline Atribut & Nilai Total & $\begin{array}{c}\text { Nilai Rata- } \\
\text { Rata }\end{array}$ \\
\hline A1 & 1132 & 2,950 \\
A2 & 1247 & 3,247 \\
A3 & 1250 & 3,260 \\
A4 & 1218 & 3,170 \\
A5 & 1250 & 3,260 \\
A6 & 1208 & 3,150 \\
A7 & 1313 & 3,420 \\
A8 & 1279 & 3,330 \\
A9 & 1296 & 3,380 \\
A10 & 1222 & 3,180 \\
A11 & 1230 & 3,200 \\
A12 & 1296 & 3,380 \\
A13 & 1169 & 3,040 \\
A14 & 1341 & 3,490 \\
\hline
\end{tabular}




$$
\begin{aligned}
\mathrm{IKM}= & (2,950 \times 0,071)+(3,247 \times 0,071)+ \\
& (3,260 \times 0,071)+(3,170 \times 0,071)+ \\
& (3,260 \times 0,071)+(3,150 \times 0,071)+ \\
& (3,420 \times 0,071)+(3,330 \times 0,071)+ \\
& (3,380 \times 0,071)+(3,180 \times 0,071)+ \\
& (3,200 \times 0,071)+(3,380 \times 0,071)+ \\
& (3,040 \times 0,071)+(3,490 \times 0,071)= \\
& 3,246
\end{aligned}
$$

IKM Konversi $=3,246$ x $25=81,15$

Dari hasil perhitungan IKM di atas, maka diketahui bahwa kualitas pelayanan pada Puskesmas 24 jam tingkat kecamatan di Jakarta adalah Baik.

\section{Importance Performance Analysis (IPA)}

Importance Performance Analysis (IPA) digunakan untuk mengetahui kesesuaian antara tingkat kepentingan dengan tingkat kepuasan masyarakat pengguna layanan jasa Puskesmas 24 jam tingkat kecamatan di Jakarta. Importance Performance Analysis dilakukan dengan menghitung skor total kinerja pelayanan dan kepentingan konsumen. Selanjutnya dilakukan perhitungan nilai rata-rata skor kinerja dan rata-rata skor kepentingan [10]. Perhitungan tingkat kesesuaian antara tingkat kepentingan dengan tingkat kepuasan masyarakat dapat dilihat pada Tabel 3.

Tabel 3. Tingkat Kesesuaian

\begin{tabular}{cccc}
\hline Atribut & $\begin{array}{c}\text { Nilai } \\
\text { Total } \\
\text { Tingkat } \\
\text { Kepuasan }\end{array}$ & $\begin{array}{c}\text { Nilai Total } \\
\text { Tingkat } \\
\text { Kepentingan }\end{array}$ & $\begin{array}{c}\text { Tingkat } \\
\text { Kesesuaian }\end{array}$ \\
\hline A1 & 1132 & 1443 & $78,45 \%$ \\
A2 & 1247 & 1363 & $91,49 \%$ \\
A3 & 1250 & 1346 & $92,87 \%$ \\
A4 & 1218 & 1235 & $98,62 \%$ \\
A5 & 1250 & 1352 & $92,46 \%$ \\
A6 & 1208 & 1423 & $84,89 \%$ \\
A7 & 1313 & 1384 & $94,87 \%$ \\
A8 & 1279 & 1372 & $93,22 \%$ \\
A9 & 1296 & 1424 & $91,01 \%$ \\
A10 & 1222 & 1402 & $87,16 \%$ \\
A11 & 1230 & 1416 & $86,86 \%$ \\
A12 & 1296 & 1379 & $93,65 \%$ \\
A13 & 1169 & 1185 & $98,65 \%$ \\
A14 & 1341 & 1413 & $94,90 \%$ \\
\hline
\end{tabular}

Untuk membuat Importance Performance Matrix dibutuhkan nilai rata-rata dari tingkat kepentingan dan tingkat kepuasan. Hasil perhitungan nilai rata-rata tingkat kepentingan dan tingkat kepuasan dapat dilihat pada Tabel 4.

Tabel 4. Nilai Rata-Rata Tingkat Kepentingan dan Tingkat Kepuasan

\begin{tabular}{ccc}
\hline Atribut & $\begin{array}{c}\text { Nilai Rata-Rata } \\
\text { Tingkat } \\
\text { Kepentingan }\end{array}$ & $\begin{array}{c}\text { Nilai Rata-Rata } \\
\text { Tingkat Kepuasan }\end{array}$ \\
\hline A1 & 3,760 & 2,950 \\
A2 & 3,550 & 3,247 \\
A3 & 3,510 & 3,260 \\
A4 & 3,220 & 3,170 \\
A5 & 3,520 & 3,260 \\
A6 & 3,710 & 3,150 \\
A7 & 3,600 & 3,420 \\
A8 & 3,570 & 3,330 \\
A9 & 3,710 & 3,380 \\
A10 & 3,650 & 3,180 \\
A11 & 3,690 & 3,200 \\
A12 & 3,590 & 3,380 \\
A13 & 3,090 & 3,040 \\
A14 & 3,680 & 3,490 \\
\hline Rata- & 3,560 & 3,246 \\
Rata & & \\
\hline
\end{tabular}

Dari atribut-atribut tersebut kemudian dilakuka analisis Importance Performance Analysis dan dijabarkan kedalam diagram kartesius sehingga menghasilkan Importance Performance Matrix [11] yang dapat dilihat pada Gambar 5.

Berdasarkan gambar Importance Performance Matrix diatas dapat diketahui bahwa atribut A1, A6, A10, dan A11 masuk dalam kuadran 1 (Concentrate These), yang memuat faktor-faktor yang dianggap penting oleh pelanggan, tetapi pada kenyataannya belum sesuai dengan harapan pelanggan. Atribut A7, A8, A9, A12, A14 masuk ke dalam kuadran 2 (Keep Up The Good Work), atribut A4 dan A13 masuk ke dalam kuadran 3 (Low Priority), dan atribut A2, A3, A5 masuk ke dalam kuadran 4 (Possible Overkill).

\section{X-Matrix Hoshin Kanri}

Berdasarkan hasil perhitungan Indeks Kepuasan Masyarakat (IKM) dan juga Importance Performance Matrix, maka selanjutnya akan dilakukan perancangan strategi peningkatan kualitas pada Puskesmas 24 jam tingkat kecamatan di Jakarta dengan menggunakan metode $X$-Matrix Hoshin Kanri. Dari X-Matrix Hoshin Kanri ini, didapatkan 
beberapa usulan strategi yaitu melakukan seleksi terhadap kandidat kepala puskesmas, membuat SOP untuk menjadi standar pelayanan puskesmas, pemberian sanksi bagi petugas pelayanan yang lalai dalam melakukan tugasnya, dan pembuatan alur prosedur pelayanan agar pasien mendapat gambaran prosedur dengan jelas dan meletakkannya disetiap ruangan. Pengembangan strategi dengan menggunakan X-Matrix Hoshin Kanri dapat dilihat pada Lampiran.

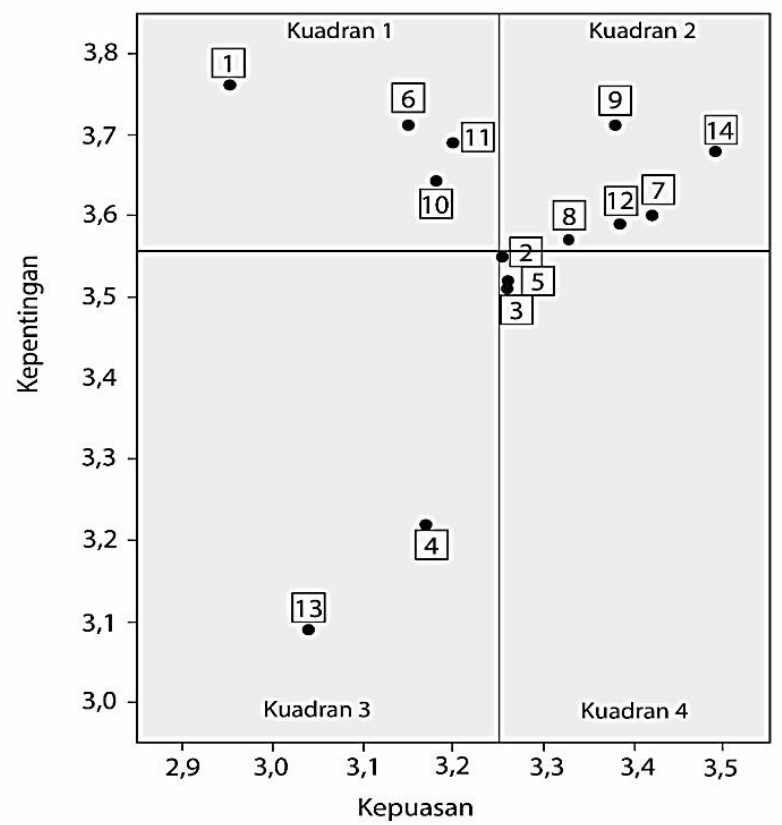

Gambar 5. Importance Performance Matrix

\section{KESIMPULAN}

Berdasarkan hasil penelitian yang dilakukan, dari 384 responden didapatkan hasil nilai Indeks Kepuasan Masyarakat sebesar 81,15 yang berarti menurut responden kualitas pelayanan Puskesmasn 24 jam tingkat kecamatan di Jakarta sudah dianggap baik.

Dari hasil Importance Performance Matrix, atribut A1, A6, A10, dan A11 masuk dalam kuadran 1 (Concentrate These). Kuadran 1 memuat faktor-faktor yang dianggap penting oleh pelanggan, tetapi pada kenyataannya belum sesuai dengan harapan pelanggan, sehingga atribut-atribut ini harus lebih diperhatikan bagi pengelola Puskesmas karena dianggap belum sesuai dengan harapan pasien.

Dari X-Matrix Hoshin Kanri ini, didapatkan beberapa usulan strategi yaitu melakukan seleksi terhadap kandidat kepala puskesmas, membuat SOP untuk menjadi standar pelayanan puskesmas, pemberian sanksi bagi petugas pelayanan yang lalai dalam melakukan tugasnya, dan pembuatan alur prosedur pelayanan agar pasien mendapat gambaran prosedur dengan jelas dan meletakkannya disetiap ruangan.

\section{DAFTAR PUSTAKA}

[1]. Permenkes Nomor 75 Tahun 2014 tentang Puskesmas

[2]. Pohan, Imbalo S. 2004. Jaminan Mutu Layanan Kesehatan: Dasar-Dasar Pengertian dan Penerapan. Jakarta: Penerbit Buku Kedokteran EGC. Pustaka Utama.

[3]. Ghozali, Imam. 2013. Aplikasi Analisis Multivariete dengan Program IBM SPSS 23. Semarang : Badan Penerbit Universitas Diponogoro.

[4]. Siregar, Syofian. 2013. Metode Penelitian Kuantitatif: Dilengkapi dengan Perbandingan Perhitungan Manual dan SPSS. Jakarta: Kencana Prenamedia Group.

[5]. Keputusan Menteri Pendayagunaan Aparatur Negara Nomor: KEP/25/M.PAN/2/2004.

[6]. Nugraha, R., Harsono, A., Adianto, H. 2014. Usulan Peningkatan Kualitas Pelayanan Jasa pada Bengkel " $X$ " Berdasarkan Hasil Matrix ImportancePerformance Analysis (Studi Kasus di Bengkel AHASS PD. Sumber Motor Karawang). Jurnal Teknik Industri Institut Nasional. No. 03 Vol. 01 Januari 2014. ISSN : 2338-5081.

[7]. Jackson, Thomas L. 2006. Hoshin Kanri for the Lean Enterprise: Developing Competitive Capabilities and Managing Profit. New York: Productivity Press.

[8]. Santoso, Singgih. 2010. Statistik Nonparametrik. Jakarta: PT Elex Media Komputindo.

[9]. Sujatmiko, dkk. 2013. Upaya Peningkatan Pelayanan Terhadap Kepuasan Mahasiswa Berdasarkan Hasil Analisis Metode Servqual dan Regresi Linear Berganda (Studi Kasus Jurusan 
Analisis Kualitas Pelayanan Puskesmas Berdasarkan Indeks Kepuasan Masyarakat dan Importance Performance Matrix

(Studi Kasus: Puskesmas 24 Jam Tingkat Kecamatan di Jakarta)

Lithrone Laricha, Andres dan Hilda Setia Dharma

Teknik Mesin Universitas di Malang. Jurnal Teknik Universitas Brawijaya. Vol. 1 No. 1 Tahun 2013. ISSN 2338-3925.

[10]. Yola, Melfa dan Duwi Budianto. 2013. Analisis Kepuasan Konsumen Terhadap Kualitas Pelayanan dan Harga Produk pada Supermarket dengan Menggunakan Metode Importance Performance Analysis (IPA). Jurnal Optimasi Sistem Industri Vol. 12 No. 12. April 2013 : 301-309. ISSN : 2088-4842.

[11]. Hariany, Zulfida dan Rahim Matondang. 2014. Analisis Indeks Kepuasan Masyarakat (IKM) Terhadap Pelayanan Publik di Puskesmas XXX. Jurnal Teknik Industri Universitas Sumatera Utara. Vol. 5 No. 2 Maret 2014 : 17-21. 


\section{Lampiran: X-Matrix Hoshin Kanri}

\begin{tabular}{|c|c|c|c|c|c|c|c|c|c|c|c|c|c|c|}
\hline \multicolumn{4}{|c|}{ Correlation/Contribution } & & \multicolumn{5}{|c|}{ Correlation/Contribution } & \multicolumn{5}{|c|}{ Accountability } \\
\hline$\odot$ & 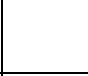 & . & 更 & $\begin{array}{l}\text { Kepala puskesmas harus memiliki pengalaman masa kerja puskesmas minimal } 2 \text { tahun } \\
\text { dan telah mengikuti pelatihan manajemen puskesmas }\end{array}$ & ○ & & & & & $\odot$ & & & & \\
\hline & ○ & & & $\begin{array}{l}\text { Melakukan pelatihan bagi para petugas pelayanan tentang manajemen dan softskill } \\
\text { khususnya komunikasi }\end{array}$ & & $\odot$ & & 0 & & & ○ & $\mathrm{O}$ & O & \\
\hline & & & O & Penentuan alur prosedur pelayanan & & & O & & & & & O & O & \\
\hline & $\Delta$ & $\mathrm{O}$ & & Petugas ramah dan sopan kepada pasien & & & & ○ & & & $\mathrm{O}$ & $\mathrm{O}$ & $\mathrm{O}$ & $\mathrm{O}$ \\
\hline & & & $\odot$ & $\begin{array}{l}\text { Menaruh banner alur prosedur pelayanan di tiap ruangan di puskesmas di tempat yang } \\
\text { mudah dilihat }\end{array}$ & & & ○ & & & & & & & $\Delta$ \\
\hline & $\Delta$ & & & $\begin{array}{l}\text { Ada petugas yang bertugas sebagai informasi bagi pasien agar mudah mendapatkan } \\
\text { informasi }\end{array}$ & & & O & & O & & & & & $\Delta$ \\
\hline & $\Delta$ & O & & Petugas harus adil dalam melayani pasien & & O & & ○ & $\mathrm{O}$ & $\Delta$ & $\Delta$ & $\Delta$ & $\Delta$ & $\Delta$ \\
\hline \multirow[b]{2}{*}{ 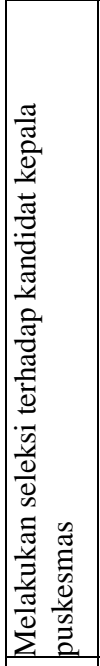 } & \multirow[b]{2}{*}{ 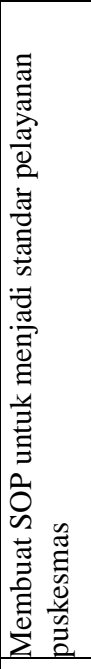 } & \multirow[b]{2}{*}{ 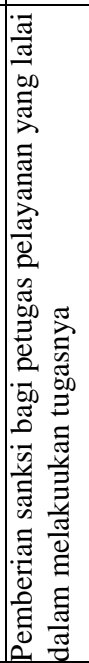 } & \multirow[b]{2}{*}{ 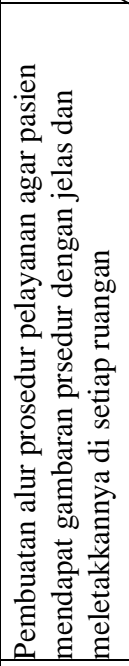 } & \multirow{2}{*}{ Strategies } & \multirow[b]{2}{*}{ 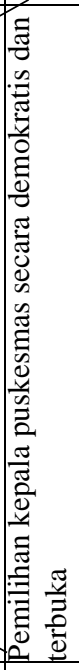 } & \multirow[b]{2}{*}{ 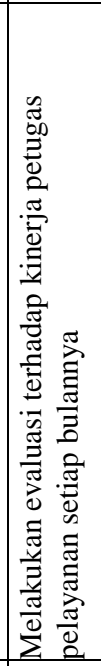 } & \multirow[b]{2}{*}{ 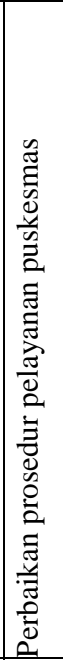 } & \multirow[b]{2}{*}{ 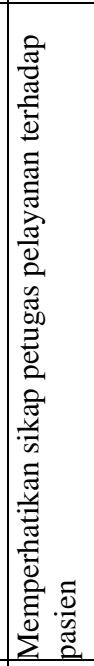 } & \multirow[b]{2}{*}{ 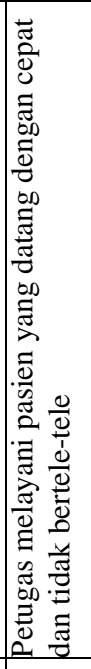 } & \multicolumn{5}{|c|}{ Team Members } \\
\hline & & & & & & & & & & 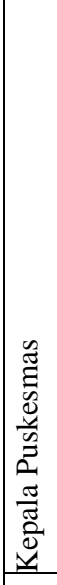 & 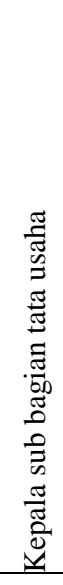 & 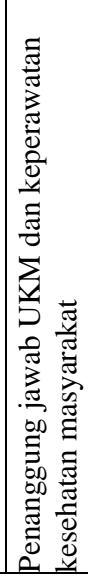 & 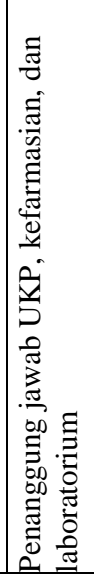 & 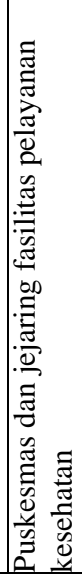 \\
\hline \multirow[t]{5}{*}{$\odot$} & O & & & $\begin{array}{l}\text { Kepala puskesmas dapat mengontrol kinerja bawahannya dan bertanggung jawab akan kinerja } \\
\text { Puskesmas }\end{array}$ & $\odot$ & & & & & \multirow{9}{*}{\multicolumn{5}{|c|}{$\begin{array}{l}\text { KETERANGAN } \\
\text { ○: hubungan kuat atau } \\
\text { pemimpin tim } \\
\text { ○: hubungan yang tidak terlalu } \\
\text { kuat atau anggota tim inti } \\
\Delta: \text { hubungan yang lemah atau } \\
\text { anggota tim }\end{array}$}} \\
\hline & & & O & Pasien atau pengunjung puskesmas merasa mudah dalam mengurus persyaratan pelayanan & & O & & & & & & & & \\
\hline & & & ○ & Pasien atau pengunjung puskesmas dapat memahami alur prosedur pelayanan puskesmas & & O & ○ & & & & & & & \\
\hline & ○ & ○ & & Para petugas pelayanan di puskesmas melakukan perbaikan kinerja yang kurang baik & & O & O & & & & & & & \\
\hline & $\mathrm{O}$ & $\mathrm{O}$ & & Pasien dapat mendapatkan kesamaan perlakuan pelayanan dari petugas & & $\Delta$ & & O & & & & & & \\
\hline$\Delta$ & $\mathrm{O}$ & & & Pasien merasa puas atas pelayanan kesehatan di puskesmas & & & & $\mathrm{O}$ & $\Delta$ & & & & & \\
\hline & O & O & & Pasien mendapatkan pelayanan kesehatan yang aman & & $\odot$ & & & & & & & & \\
\hline & $\mathrm{O}$ & 0 & & Petugas pelayanan cepat tanggap menangani pasien & & O & & 0 & 0 & & & & & \\
\hline \multicolumn{4}{|c|}{ Correlation/Contribution } & & \multicolumn{5}{|c|}{ Correlation/Contribution } & & & & & \\
\hline
\end{tabular}

